\title{
Efraín Bartolomé: La biblioteca dinámica del Instituto Nacional de Enfermedades Respiratorias
}

\author{
Efraín Bartolomé: National Institute of respiratory \\ diseases the dynamic library
}

\author{
José Luis Sandoval-Gutiérrez*
}

*Instituto Nacional de Enfermedades Respiratorias Ismael Cosío Villegas, Ciudad de México, México.

\begin{abstract}
El libro es fuerza, es valor, es alimento; antorcha del pensamiento y manantial del amor.

Rubén Darío Poesía y prosa
\end{abstract}

Recién, el Laboratorio de Fisiología Respiratoria del Instituto Nacional de Enfermedades Respiratorias Ismael Cosío Villegas de la Ciudad de México, encabezado por la Dra. Laura Gochicoa, decidió brindar a los pacientes y sus familiares la posibilidad de préstamo de libros en la sala de espera; los cuales al irse acumulando (más de 500) llevó a la idea de formar una biblioteca. La biblioteca ha sido inaugurada y lleva el nombre del poeta Efraín Bartolomé, el maestro nos ofrece el siguiente mensaje:

«Hace dos meses, exactamente el 02 de septiembre del año en curso, recibí esta invitación:

Querido Maestro:

Esperando que se encuentre bien, quisiera invitarlo para que nos hiciera el honor de inaugurar la biblioteca del Instituto Nacional de Enfermedades Respiratorias (INER)...

Se me pedía, también, que después de dicho acto, diera un recital.

Acepté ambas cosas con curiosidad y con alegría.

El día 30 de octubre, antier, se llevó a cabo el acto.

Guadalupe y yo llegamos puntualmente y nos recibieron la Dra. Laura Gochicoa, Jefa del Departamento de Fisio-

Correspondencia:

Dr. José Luis Sandoval-Gutiérrez

Instituto Nacional de Enfermedades Respiratorias Ismael Cosío

Villegas, Ciudad de México.

Correo electrónico: sandovalgutierrez@gmail.com logía Respiratoria y su esposo el Dr. Juan Manuel Grosso Espinosa, Jefe del Departamento de Consulta Externa del Instituto Nacional de Perinatología.

Me enorgullece decir que el Dr. Grosso es mi lector.

Fuimos de sorpresa en sorpresa:

Primera: se trataba de inaugurar la Biblioteca Dinámica, pequeña colección literaria que comienza su existencia con quinientos libros.

Segunda: nos esperaba en los pasillos un medio centenar de profesionales de la medicina, de México y de América Latina, que se habían reunido para la ceremonia.

Tercera: habló primero la Dra. Gochicoa y a continuación el Dr. Jorge Salas Hernández, director del INER.

Cuarta: iSorpresa mayor! A la entrada de la sala había una placa donde puede leerse que la naciente biblioteca iestá dedicada a mí!

En el Instituto Nacional de Enfermedades Respiratorias ihacen alusión al aire puro de la selva que les aporta la poesía!

Yo agradecí con estas palabras:

Queridos amigos:

En los largos pasillos de hospital, la soledad parece condensarse.

El dolor del paciente y la ansiedad de la familia, se agudizan con el internamiento y con las limitaciones a la libertad de acción.

Por eso es tan importante que tengamos la opción de romper la soledad y no hay mejor herramienta para eso que la lectura.

En mi historia como lector puedo contarles que la poesía, la más señorial de las artes, le ha dado sentido a mi vida.

Mi alma ha sido forjada con poemas.

Al principio, como nos pasa a la gran mayoría, leía todo lo que caía en mis manos. 


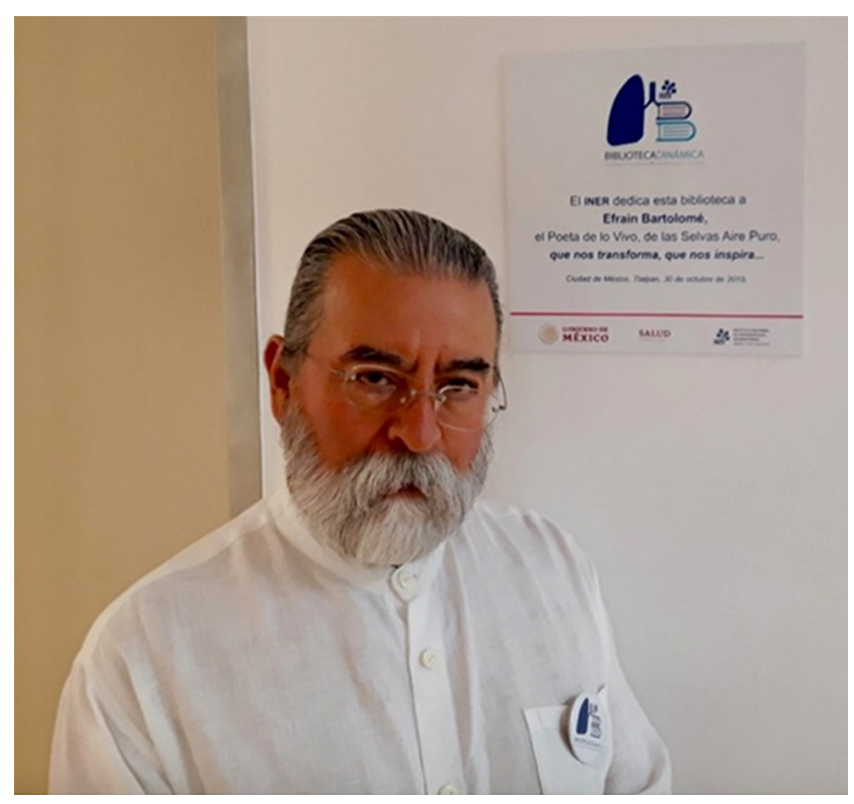

Figura 1: Poeta Efraín Bartolomé (Ocosingo, Chiapas, 1950). Sistema Nacional de Creadores, International Latino Arts Award.

Pero a medida que más exponemos el alma a la estimulación, el espíritu nos va pidiendo niveles de calidad cada día más altos. Habiendo tocado la maravilla, cada vez resulta más difícil contentarnos con menos.

Los poetas que me formaron ya murieron y, sin embargo, gracias a los libros, aún puedo hablar con ellos.

Leo continuamente a Homero, leí a Virgilio, he leído a Garcilaso, a Rubén Darío, a don Antonio Machado, a Salvador Díaz Mirón, a Ramón López Velarde, a Octavio Paz, a Jaime Sabines, y a algunos miles más...

Y al hacerlo hablo con ellos.

Don Francisco de Quevedo, allá en su España, se retiraba, a veces por su voluntad y alguna vez porque sufrió prisión domiciliaria, a un pueblo de La Mancha llamado Torre de Juan Abad.

Ahí, rodeado de pocos libros, pero de alto nivel, dialogaba a su vez con sus poetas formadores.

Por eso dijo inmejorablemente:

Retirado en la paz de estos desiertos, con pocos, pero doctos libros juntos, vivo en conversación con los difuntos, y escucho con mis ojos a los muertos.

Fíjense bien en eso: vivo en conversación con los difuntos / y escucho con mis ojos a los muertos.

Eso es leer: conversar con los difuntos y escucharlos con los ojos.

Tal vez por eso, Jorge Luis Borges escribió, en su excelso Poema de los dones, las siguientes palabras aladas:
Nadie rebaje a lágrima o reproche esta declaración de la maestría de Dios, que con magnífica ironía me dio a la vez los libros y la noche.

Escribió el poema cuando dirigía la Biblioteca Nacional de Argentina y al mismo tiempo iba perdiendo la vista irremisiblemente.

Y no se queja, acepta el decreto divino: Nadie rebaje a lágrima o reproche / esta declaración de la maestría / de Dios, que con magnífica ironía / me dio a la vez los libros y la noche.

Y sigue:

Lento en mi sombra, la penumbra hueca exploro con el báculo indeciso, yo, que me figuraba el Paraíso bajo la especie de una biblioteca.

Ahí estaba el poeta, en aquel recinto que es el paraíso para un lector... pero sin ojos la biblioteca es ciega.

Por eso me da tanto gusto estar aquí, en la inauguración de esta biblioteca del INER: donde médicos, enfermeras, paramédicos, afanadoras, empleados administrativos, pero principalmente pacientes y familiares, aún tienen ojos con los cuales pueden oír a los altos espíritus que ya no están corporalmente en el mundo, y entrar en conversación con ellos que se quedaron en sus mejores palabras.

Recuerden esto, también: los poetas, los escritores en general, ya hablaron y nos dejaron sus mejores palabras. Para bien de nuestro espíritu es mejor responderles.

¿Por qué? Porque ellos ya cumplieron y, si no los escuchamos con los ojos, no estaremos cumpliendo nuestra parte.

Para que quede aún más claro, sopesen, como remate, estas palabras de Rosario Castellanos:

La sordera no es lo que hace al silencio.

Lo que hace al silencio es la mudez.

Y después de declarar antisolemnemente inaugurado este pequeño paraíso, pasen, escuchen con los ojos, y entren en conversación con los altos espíritus que aquí los aguardan.

iBuena suerte!

CDMX, 30 de octubre de 2019.»

Esta nueva iniciativa cultural para el beneficio de nuestros pacientes es bienvenida, se espera que en el futuro sea el camino de nuevos acervos bibliográficos en más departamentos y otras unidades médicas. 